\title{
Study the Influence of the Anodizing Process Parameters on the Anodized Copper Hardness
}

\author{
M.H. Mahmood 1a, Suryanto 1,b, Muataz H. F. Al Hazza ${ }^{1, c}$ and Farag I Haider 1,d \\ ${ }^{1}$ Department of Manufacturing and Material Engineering, International Islamic University Malaysia, Kuala Lumpur, Malaysia
}

\begin{abstract}
The metals anodization process used to enhance the surface hardness and corrosion resistance. This study developed a durable hard Nano copper oxide coating on copper using anodization technique in solutions of 0.1 to 0.5 $\mathrm{M}$ oxalate concentrations and 0 to $24^{\circ} \mathrm{C}$ operating temperature. The settings of the process parameters determined by using Taguchi's experimental design method. The EDX and XRD results confirm the formation of cupric oxide coating with monoclinic lattice crystalline structures. The FESEM results for the coated samples showed that the grain size was in the range between 25 to $68 \mathrm{~nm}$. Microhardness tests for the anodized copper samples characterized by microhardness tester. Analysis of Variance for the orthogonal arrays of Taguchi identified that the most affecting parameter on the microhardness of the coating was the anodizing temperature. The results show that the hardness of the anodized coating was decreased with the anodizing temperature, where maximum hardness, with smaller grain size, were produced at lower anodizing temperatures.
\end{abstract}

\section{Introduction}

Anodization is an electrochemical process used to create a uniform anodic metal oxide coating on the metal surface. In this electrochemical process, the sample set as the anode part of the electrical circuit. The metal surface after the anodization process converted to a thick and hard oxide layer, which provides some degree of corrosion protection for the underlying metal. Recently Nano copper oxide coating is being developed for various applications as, gas detection sensors, superhydrophobic surfaces, specialized solar cells $[1,2,3]$. Other researchers study the increasing of the surface hardness and the corrosion resistance of metals by anodization process $[4,5]$. The hardness of the copper oxide is superior to that of the pure copper, and it is a highly nonconductive material. Therefore, it improves the hardness of the anodized coated surface and its corrosion protection. According to Mindat.org, the hardness of the pure copper surface is between 77 and 99, (about $80 \mathrm{HV}$ ) (2.5-3 Mohs) [6], while copper oxide Hardness is (190300 HV) (3.5-4 Mohs) [7, 8]. The latest study on copper anodization [9] showed that in anodization the copper electrode passivized and the dissolution of copper reduced. It recommends for further research studies for developing the surface properties to improve copper corrosion resistance [9]. The present work, investigate the influence of the most affecting parameters of electrolyte concentration, temperature and applied voltage on coating hardness.

\section{Experimental Procedure}

\subsection{Copper anodization}

The experimental work starts with the copper anodization process in oxalate containing solutions. Copper foil samples, purity $99.5 \%$ ASTM B280, of $0.12 \mathrm{~mm}$ thickness and $1 \mathrm{~cm} \times 2 \mathrm{~cm}$ dimensions. The samples polished and cleaned according to the standard of ASTM, 2003 , then it washed with tap water, distilled water and acetone. The anodization process parameters have been chosen in the ranges of, oxalate concentrations $0.1-0.5$ $\mathrm{M}$, electrolyte temperatures $0-24^{\circ} \mathrm{C}$ and applied voltage 7.5 - $9 \mathrm{~V}$. Experiments were performed using $\mathrm{Ag} / \mathrm{AgCl}$ (SSE) as a reference electrode and Platinum foil as the counter electrode. Anodization measurements performed by Auto Lab Potentiostat/Galvanostat, PGSTATAUT86037, supported (ANOVA Software). The anodization was carried out using Linear Sweep Voltammetry (LSV) at scan rate $0.02 \mathrm{~V} / \mathrm{S}$.

\subsection{Taguchi's Design of Experiment}

Taguchi DOE is the most efficient and powerful over other traditional analytical methods. It is a systematic approach to investigate system or process. A series of experimental tests designed with a planned input variables change for a process or system. The effects of these changes on detailed output responses then evaluated. Four levels for each input variable are selected. These levels represent the desired range for the effect of the 
variable that wants to be studied within. The response for each run are measured, then results analyzed by comparing the differences between response output readings for different variables input groups. These differences attributed to the input variables acting alone as a single effect. The software used for generating the Taguchi's orthogonal array is Minitab 17. The main advantage of Taguchi DOE is to reduce the experiments number that has to test as compared with the full factorial method. The total tests to be conducted for three factors and four levels combinations in full factorial method is 64, as compared with Taguchi method that only 16 operations must be tested. These experiments investigate the effects of the main anodization factors on the anodized copper hardness results, an experimental strategy Design of Experiments, DOE, for the running tests at various levels of the factors was used to obtain the optimal anodizing condition with highest coating hardness.

For studying the influence of the process parameters during copper anodization process in oxalate containing solutions, three factors and four levels were used. The four levels parameters of the anodizing experiments were $0.1,0.23,0.36,0.5 \mathrm{M}$ oxalate concentrations, $0,8,16,24^{\circ}$ $\mathrm{C}$ anodizing temperatures, and 7.5, 8, 8.5, $9 \mathrm{~V}$ applied voltage, as shown in Table 1.

Table 1. Anodization parameters and their levels

\begin{tabular}{|c|c|c|c|c|c|}
\hline & \multicolumn{4}{|c|}{ Levels and values } & \multirow{2}{*}{ Parameters } \\
\cline { 2 - 5 } & $\begin{array}{c}\text { Level } \\
1\end{array}$ & $\begin{array}{c}\text { Level } \\
2\end{array}$ & $\begin{array}{c}\text { Level } \\
3\end{array}$ & $\begin{array}{c}\text { Level } \\
4\end{array}$ & \\
\hline $\begin{array}{c}\text { Electrolyte } \\
\text { Concentration } \\
(\mathrm{M})\end{array}$ & 0.1 & 0.23 & 0.36 & 0.5 & \\
\hline $\begin{array}{c}\text { Temperature } \\
\left({ }^{\circ} \mathrm{C}\right)\end{array}$ & 0 & 8 & 16 & 24 & $\begin{array}{c}\text { Micro } \\
\text { hardness }\end{array}$ \\
\hline $\begin{array}{c}\text { Applied } \\
\text { Voltage } \\
(\mathrm{V})\end{array}$ & 7.5 & 8.0 & 8.5 & 9.0 & \\
\hline
\end{tabular}

In this research, sixteen experiments conducted at different parameter levels. Orthogonal array L16 was used, which has sixteen rows corresponding to the tests numbers. For monitoring the effects of anodization parameters on the hardness of the anodized copper coating, this study considered the surface microhardness as the primary output response.

\section{Results and discussions}

\subsection{Coating Hardness Characterization}

To investigate copper anodization parameters affecting on anodized copper surface hardness. The microhardness of the anodized copper samples tested on Automatic microhardness tester, MHT- Smart by Omnitech. The hardness tests were carried out by pyramid indenter with an applied load of 100 gm.f. The indentation length determined using optical microscopy and image-j software used for analyzing the resulted image. The tests carried out at five different locations on all the samples surfaces to avoid the possibility of any error readings. The indentation length determined using optical microscopy and image- $\mathrm{j}$ software used for analyzing the resulted image. The average measured microhardness was $170 \mathrm{Hv}$.

\subsection{Morphological analysis}

The surface morphology and composition of the fabricated anodized copper coating, characterized using energy dispersive X-ray spectroscopy, EDX, X-ray diffraction (XRD) and Field Emission Scanning Electron Microscope, FESEM. The EDX results of coated and uncoated copper samples show the increase of the oxygen content in the coated sample, as illustrated in figure 1.

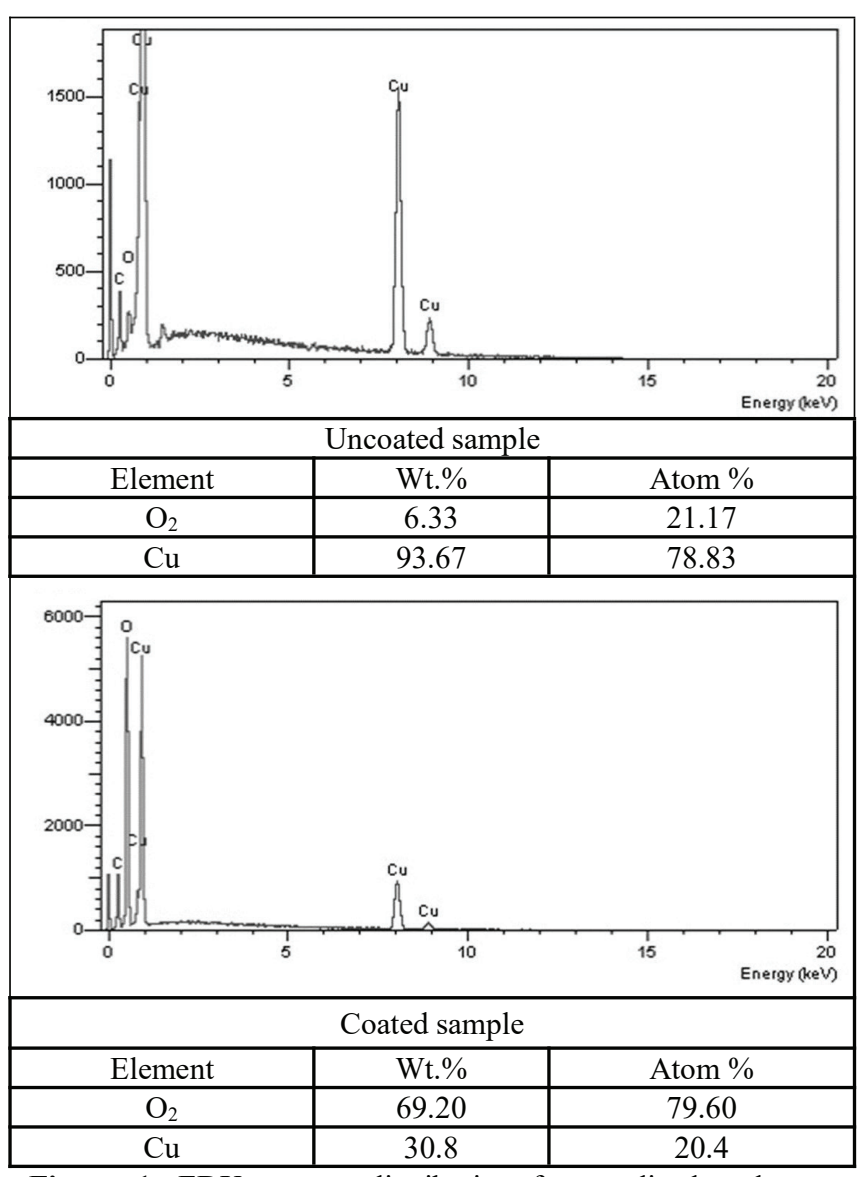

Figure 1. EDX spectra distribution for anodized and nonanodized coating

The X-ray diffraction pattern graphs produced from the reflected spectrum on the anodized copper samples show diffraction peak identical with the standard card of cupric oxide spectrum peaks JCPDS 05-0661. The prominent peaks in the XRD diffraction pattern for the anodized copper samples at 38 and $65^{\circ}$, refers to the formation of cupric oxide $\mathrm{CuO}$ on the coated surface with a preferred orientation plans (111) and (022), as illustrated in figure 2. 


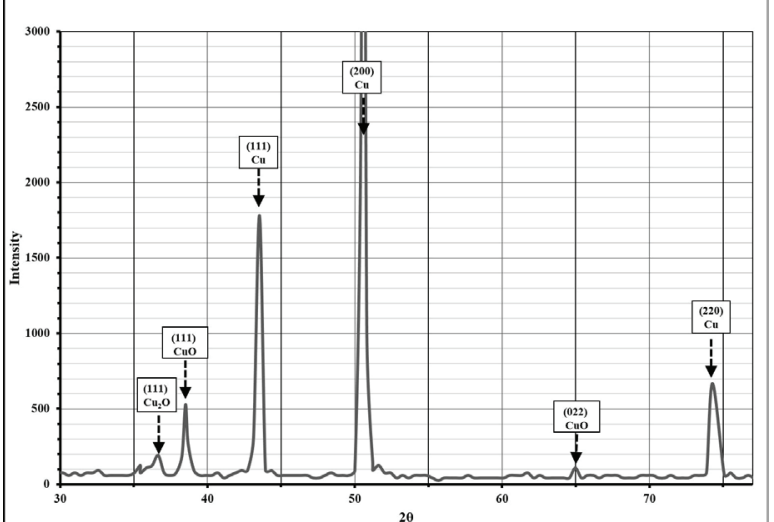

Figure 2. XRD Analysis of anodized copper samples

FESEM, micrographic results of anodized specimens, show a uniformly distributed Nanoparticles of different grain sizes on the surface as illustrated in figure 3 . The analyzed FESEM results using, Image $\mathrm{J}$, software produced that the coating grain sizes were in the range between 25 to $68 \mathrm{~nm}$.

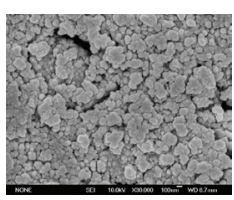

a

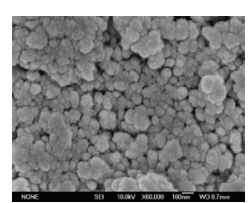

b

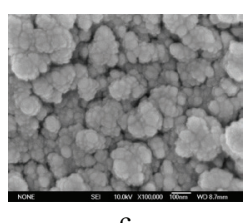

Figure 3. FESEM images for copper oxide Nanoparticles with magnifications of a; 30,000, b; 60,000 and c; 100,000

\subsection{Effects of anodization parameters on the Coating hardness}

After the copper anodizing experiments completed, the anodized coating microhardness measured by fully automatic microhardness tester MH Smart by Omnitech. The anodized coating experimental results were analyzed using Design Expert, Minitab 17, and JMP11.0.0 software to evaluate the effects of the anodization parameters of oxalate concentration, temperatures, and applied voltage on the microhardness of the anodized coating. According to Taguchi analysis method, the results were analyzed based on the signal - to - noise, $\mathrm{S} / \mathrm{N}$, ratio response variation, to minimize the change of the characterization quality due to the uncontrollable parameter. The coating hardness response considered as a quality characteristic with the concept of "larger-thebetter":

$$
\mathrm{S} / \mathrm{N}=-10 \times \log \left[1 / \mathrm{n} \sum\left(1 / \mathrm{Y}_{\mathrm{i}}^{2}\right)\right]
$$

Where $\mathrm{n}$ is the number of observations, and $\mathrm{Yi}$ is the measured output value. The resulted output values of the surface coating hardness and their corresponding $\mathrm{S} / \mathrm{N}$ ratio listed in Table 2.
Table 2. Average hardness values along with their corresponding $\mathrm{S} / \mathrm{N}$ ratio values

\begin{tabular}{|c|c|c|c|c|c|}
\hline Exp. & $\begin{array}{c}\text { Concentration } \\
(\mathrm{M})\end{array}$ & $\begin{array}{c}\text { Temperature } \\
\left({ }^{\circ} \mathrm{C}\right)\end{array}$ & $\begin{array}{c}\text { Voltage } \\
(\mathrm{V})\end{array}$ & $\begin{array}{c}\text { Hardness } \\
(\mathrm{Hv})\end{array}$ & $\mathrm{S} / \mathrm{N}$ \\
\hline 1 & 0.1 & 0 & 7.5 & 192 & 45.67 \\
\hline 2 & 0.1 & 8 & 8 & 190 & 45.58 \\
\hline 3 & 0.1 & 16 & 8.5 & 188 & 45.48 \\
\hline 4 & 0.1 & 24 & 9 & 186 & 45.39 \\
\hline 5 & 0.23 & 0 & 8 & 179 & 45.06 \\
\hline 6 & 0.23 & 8 & 7.5 & 177 & 44.96 \\
\hline 7 & 0.23 & 16 & 9 & 174 & 44.81 \\
\hline 8 & 0.23 & 24 & 8.5 & 172 & 44.71 \\
\hline 9 & 0.36 & 0 & 8.5 & 168 & 44.51 \\
\hline 10 & 0.36 & 8 & 9 & 165 & 44.35 \\
\hline 11 & 0.36 & 16 & 7.5 & 163 & 44.24 \\
\hline 12 & 0.36 & 4 & 8 & 160 & 44.08 \\
\hline 13 & 0.5 & 0 & 9 & 155 & 43.81 \\
\hline 14 & 0.5 & 8 & 8.5 & 156 & 43.86 \\
\hline 15 & 0.5 & 16 & 8 & 153 & 43.69 \\
\hline 16 & 0.5 & 24 & 7.5 & 145 & 43.23 \\
\hline
\end{tabular}

The values of $\mathrm{S} / \mathrm{N}$ ratio of the anodized coating hardness by factor levels shown in Table 3 .

Table 3. $\mathrm{S} / \mathrm{N}$ ratio values by levels according to the coating hardness

\begin{tabular}{|c|c|c|c|}
\hline Level & Temperature & Concentration & Voltage \\
\hline 1 & 45.53 & 44.76 & 44.52 \\
\hline 2 & 44.88 & 44.69 & 44.60 \\
\hline 3 & 44.30 & 44.56 & 44.64 \\
\hline 4 & 43.65 & 44.35 & 44.59 \\
\hline Delta & 1.88 & 0.41 & 0.12 \\
\hline Rank & 1 & 2 & 3 \\
\hline
\end{tabular}

From this result, it was concluded that the anodization parameters effect on hardness as shown in Figure 4. This plot illustrates the Signal to noise $\mathrm{S} / \mathrm{N}$ ratio as a function of the anodization parameters.

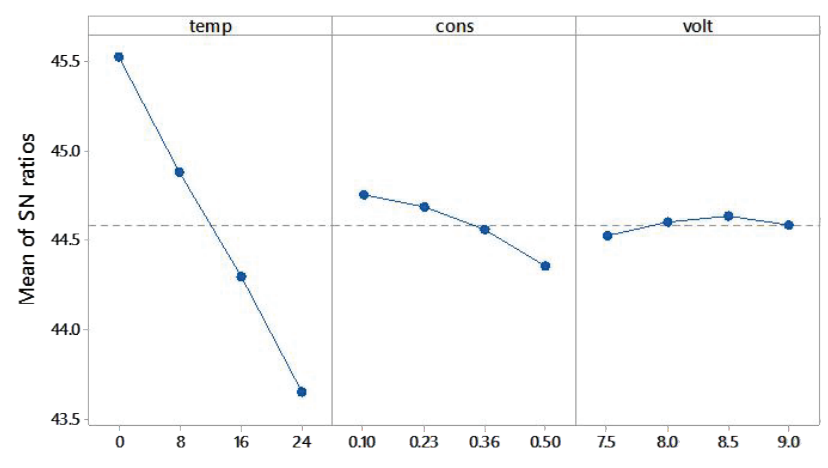

Signal-to-noise: Larger is better

Figure 4. Signal to noise $\mathrm{S} / \mathrm{N}$ plot showing the effects of anodization parameters on coating hardness

These results evaluate the effect of process parameters on the surface hardness by using Signal to noise $\mathrm{S} / \mathrm{N}$ ratio. The electrolyte temperature was the most affecting parameter on the anodized coating hardness. The oxalate concentration was the next affecting parameter, while the 
applied voltage was the less affecting parameter on the surface hardness

\subsubsection{Effect of anodizing temperature on the surface hardness}

The anodization temperature was the most affecting parameter on the hardness of the coated surface. The analysis of the results revealed that the microhardness of the coating was decreased with the increase of the anodization temperature, as shown in figure 5 . The maximum surface hardness of $190 \mathrm{HV}$ resulted at the anodized coating at $0{ }^{\circ} \mathrm{C}$, and minimum surface hardness of $150 \mathrm{HV}$ produced at $24{ }^{\circ} \mathrm{C}$, as shown in figure 5 .

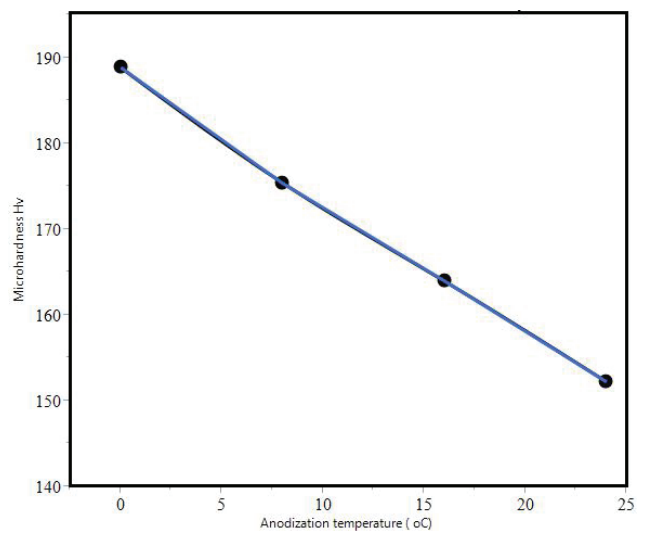

Figure 5. Anodized coating micro-hardness as a function of temperature

\subsubsection{Effects of oxalate concentration on the surface hardness}

The oxalate concentration was the second affecting parameter on the hardness of the coated surface. The analysis of the results revealed that the microhardness of the coating was slightly decreased with the increase of the anodizing oxalate concentration, as shown in figure 6 .

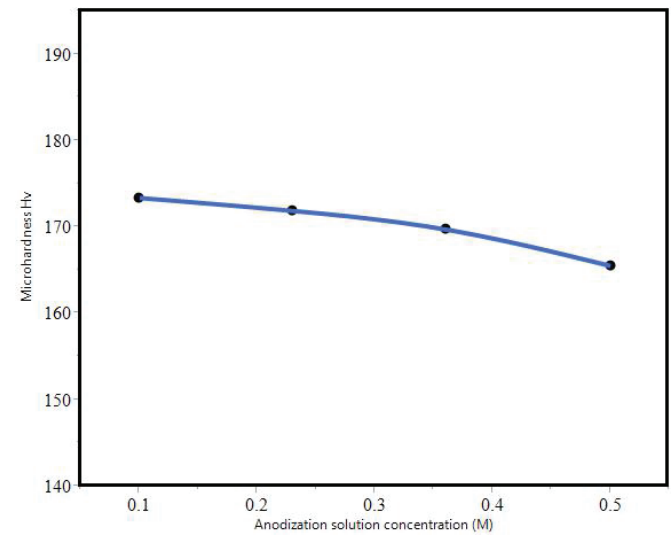

Figure 6. Microhardness of coated surface as a function of the anodizing oxalate concentration
The analysis of the results also revealed that the coated surface hardness was decreased with the increase of the anodizing temperature at the same oxalate concentration. The coated surface hardness also was reduced with the rising of the oxalate concentration at the same anodizing temperature, as shown in Figure 7. Therefore, the harder coating was produced at a lower temperature and higher oxalate concentration.

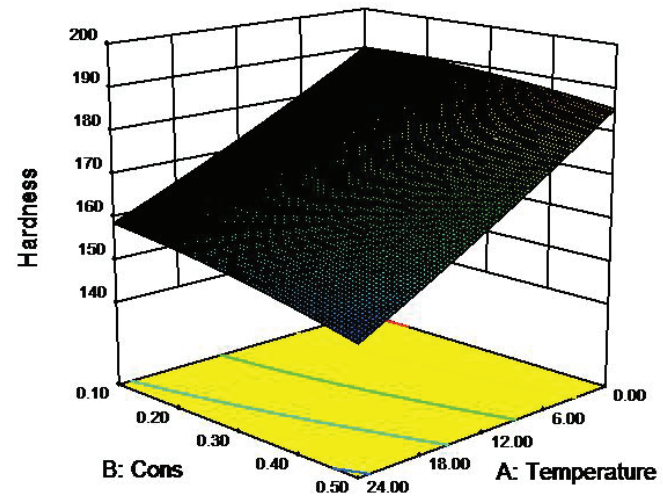

Figure 7. average hardness of coated surface as a function of (A) anodization temperature and (B) electrolyte concentration

\subsubsection{Effects of applied voltage on the coated surface hardness}

The analysis of the experimental results shows that the applied voltage was the less affecting parameter on the surface hardness. The relation between the applied voltage and the coated surface hardness was reversible. Whereas, the increase of the applied voltage was slightly decreased the surface hardness as shown in figure 8 .

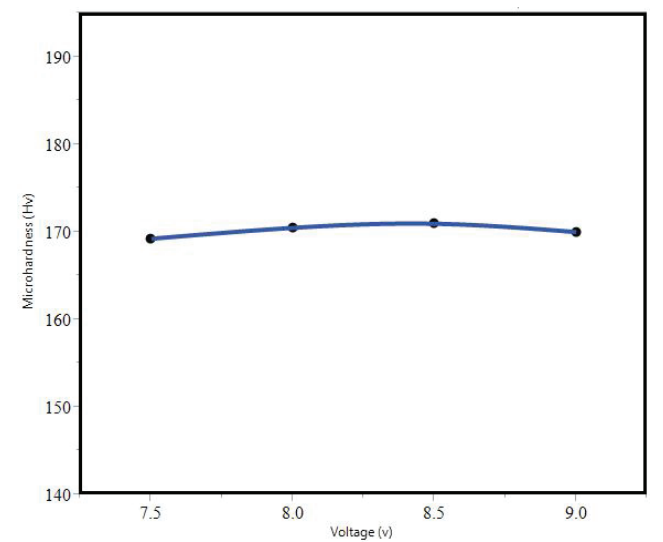

Figure 8. Anodized surface micro-hardness as a function of the anodization applied voltage

\section{Conclusions}

From this results was concluded that the anodized coating increased the surface hardness of copper and protecting it from the surrounding environment. Results show that the temperature was the most affecting parameter on the hardness of the anodized coating and the oxalate concentration was the second affecting parameter, while the applied voltage is the less affecting parameter on the coated surface hardness. 
Results show that the microhardness of the anodized coating decreased with the increase of the anodizing temperature. Moreover, it also reduced with the rising of the oxalate concentration at the same anodizing temperature. So that harder anodized copper coating produced at a lower temperature and higher oxalate concentration.

\section{References}

1. L. Xu, "Novel urchin-like CuO synthesized by a facile reflux method with efficient olefin epoxidation catalytic performance," Chem. Mater., vol. 21, no. 7, pp. 1253-1259, (2009).

2. M.S. Yong, "Natural and Biomimetic Artificial Surfaces for Superhydrophobicity, Self-Cleaning, Low Adhesion, and Drag Reduction

Dissertation," The Ohio State University, (2009).

3. H. Singh, "Fabrication and Characterization of Copper Nanowires," J. Nanosci. Nanoeng. Appl., vol. 1, no. 1, (2011).

4. N. Fredj and T. D. Burleigh, "Transpassive Dissolution of Copper and Rapid Formation of Brilliant Colored Copper Oxide Films," J. Electrochem. Soc., vol. 158, no. 4, p. C104, (2011).

5. H. Chang, "Fabrication of CuO Nanofilm preparation by Electrophoretic Deposition," vol. 4, pp. 370-373, 9, (2007).

6. P. Ivan, "Planarization composition for metal surfaces comprising an alumina hydrate abrasive," PCT/US2006/046225, (2008).

7. K. Rajiv, "Chemical-Mechanical polishing slurry for polishing of copper or silver films," US 6,821,309 B2, (2004).

8. H. Battez, "CuO, ZrO2 and $\mathrm{ZnO}$ nanoparticles as an anti-wear additive in oil lubricants," Wear, vol. 265, no. 3-4, pp. 422-428, (2008).

9. A. Romeiro, "Polyphenazine films as inhibitors of copper corrosion," J. Electroanal. Chem., vol. 688, pp. 282-288, (2013). 